\title{
Distribution of a Second Dose of Exogenous Surfactant in Rabbits with Severe Respiratory Failure
}

\author{
F. B. PLÖTZ, H. STEVENS, A. HEIKAMP, AND S. BAMBANG OETOMO \\ Department of Pediatrics, Division of Neonatology [F.B.P., H.S., S.B.O.], Central Animal Laboratory \\ [A.H.], University Hospital, Groningen, The Netherlands
}

\begin{abstract}
Newborn infants with respiratory distress who fail to respond to surfactant treatment receive a second dose of surfactant. The effect of this strategy on the distribution of surfactant to the lung is unknown. We therefore investigated the distribution of the first (100 mg/kg body weight) and second dose $(50 \mathrm{mg} / \mathrm{kg}$ body weight) of surfactant (Alveofact) in lung-lavaged rabbits $(n=6)$. We used ${ }^{141} \mathrm{Ce}$ - and ${ }^{103} \mathrm{Rn}$-labeled microspheres that were mixed with the first and second dose of surfactant, respectively. Arterial $\mathrm{PO}_{2}$ increased from $5.7 \pm 1.1$ to $10.6 \pm 2.0 \mathrm{kPa}(p<0.05)$ (mean $\pm \mathrm{SD}$ ) after the first and from $20.1 \pm 3.8$ to $30.1 \pm 2.5$ $\mathrm{kPa}(p<0.05)$ after the second dose. Thereafter the rabbits were killed, and the lungs were cut into 200 pieces. The radioactivity of $\mathrm{Ce}$ and $\mathrm{Rn}$ microspheres was measured and distribution histograms were obtained. Histograms of the first, second, and the total dose of surfactant showed similar nonuniform distribution. Correlation coefficients of the $\mathrm{Ce}$ and $\mathrm{Rn}$ radioactivity in the different lung lobes widely ranged per lung lobe per rabbit. In addition, the percentage of the number of lung pieces that
\end{abstract}

ABSTRACI received an amount of surfactant that was less than the calculated endogenous surfactant pool decreased from $12.5 \pm 3.2 \%$ to 8.5 $\pm 3.0 \%(p<0.05)$ after the first and second dose, respectively. This indicates that the second dose was directed both to areas that initially received surfactant and to areas that were still surfactantdeficient. The surfactant-deficient areas were aerated after this second dose, resulting in a further rise in $\mathrm{PO}_{2}$. We conclude that a second dose of surfactant does not lead to homogeneous distribution of surfactant but does result in a significant rise in $\mathrm{PO}_{2}$ that is probably due to increased aeration after the second dose of surfactant, which may be partially related to an additional recruitment of alveoli after the second dose of surfactant. (Pediatr Res 37: 476-481, 1995)

Abbreviations
RDS, respiratory distress syndrome
PEEP, positive end-expiratory pressure

Exogenous surfactant therapy has been shown to be beneficial in the treatment of premature infants with RDS. Collaborative studies, using either synthetic, natural, or modified surfactant, given either as prophylaxis or as rescue therapy, have shown decreases both in pulmonary morbidity and neonatal mortality (1-9). However, not all patients benefit from surfactant treatment. Some studies have reported that $22 \%$ of surfactant-treated infants failed to respond, and $11 \%$ responded only transiently $(6,10,11)$. As it was hypothesized that surfactant deficiency was responsible for the relapse, it was suggested that patients who showed deterioration after the initial response to surfactant treatment should be retreated. Some investigators advocate applying a multiple-dose treatment strategy (12-15). It has been shown that a multiple-dose treatment of surfactant reduced morbidity and mortality in patients with severe RDS.

Received February 17, 1994; accepted October 11, 1994

Correspondence: S. Bambang Octomo, M.D., Department of Pediatrics, Division of Neonatology, University Hospital, Groningen, Oostersingel 59, 9713 EZ Groningen, The Netherlands.
Recently, we have shown that exogenous surfactant is distributed to the lung in a nonuniform way, and we speculate that an inhomogeneous distribution probably promotes relapse in some patients (16). At present, it is not known how the second dose is distributed to the lung. Is the surfactant directed to areas where surfactant was deposited initially or to areas of the lung that did not receive surfactant? The aim of this study was therefore to investigate whether a second dose of surfactant promotes uniform distribution to the lung. This may explain the improved outcome in patients after multiple dose treatment.

\section{METHODS}

Animals. In six Chincilla rabbits, weighing $2.5 \pm 0.3 \mathrm{~kg}$ (mean $\pm \mathrm{SD}$ ), severe respiratory failure was induced according to the protocol that we described previously (17). In short, the rabbits were anesthetized with sodium pentobarbital (Nembutal, Abbot Laboratories, North Chicago, IL), $30 \mathrm{mg} / \mathrm{kg}$ body weight, and placed in the supine position on a heated mattress. After intubation by means of a tracheostomy, the rabbits were paralyzed with pancuronium bromide (Pavulon, 
Organon Technica, Oss, The Netherlands), $0.1 \mathrm{mg} \cdot \mathrm{kg}$ body weight, and artificially ventilated (Amsterdam Infant Ventilator MK III, Hoek Loos Co., Schiedam, The Netherlands) with $100 \%$ oxygen and in a minute volume of $400 \mathrm{~mL} \cdot \mathrm{kg}$ body weight. Respiratory rate was set at a frequency of $60 / \mathrm{min}$ with an inspiration time of $40 \%$. A catheter was introduced into the left carotid artery to measure the arterial blood pressure and to obtain samples for blood gas analysis. The lungs were subsequently lavaged five times with $35 \mathrm{~mL}$ of normal saline $\left(38^{\circ} \mathrm{C}\right)$ per $\mathrm{kg}$ of body weight. During this procedure the instillation of normal saline was stopped when the intratracheal pressure reached $3922.4 \mathrm{~Pa}\left(40 \mathrm{~cm} \mathrm{H}_{2} \mathrm{O}\right)$. The rabbits were allowed to recover from each lavage for a 5 -min period. During the lavage procedure the level of the PEEP was stepwise increased to 980.6 $\mathrm{Pa}\left(10 \mathrm{~cm} \mathrm{H}_{2} \mathrm{O}\right)$. Fifteen minutes after the lung lavage procedure, the PEEP was lowered to $490.3 \mathrm{~Pa}\left(5 \mathrm{~cm} \mathrm{H}_{2} \mathrm{O}\right)$.

Surfactant treatment. In all rabbits, two doses of bovine surfactant (Alveofact, $45 \mathrm{~g} / \mathrm{L}$, Thomae $\mathrm{GmbH}$, Biberach, Germany) were endotracheally instilled. The first surfactant dose of $100 \mathrm{mg} \cdot \mathrm{kg}$ body weight was administered $30 \mathrm{~min}$ after the last lung lavage, and the second surfactant dose of $50 \mathrm{mg} \cdot \mathrm{kg}$ body weight was administered $2 \mathrm{~h}$ later. The time interval of 2 $\mathrm{h}$ was chosen arbitrarily.

To study the distribution of the two surfactant doses separately, $1.5 \mathrm{~Bq}$ of ${ }^{141} \mathrm{Ce}$-labeled microspheres with a diameter of $15 \times 10^{-6} \mathrm{~m}$ (DuPont-New England Nuclear, Hertogenbosch, The Netherlands) were mixed with the first surfactant dose, and $1.5 \mathrm{~Bq}$ of ${ }^{103} \mathrm{Rn}$-labeled microspheres with a diameter of $15 \times$ $10^{-6} \mathrm{~m}$ (DuPont-New England Nuclear) were mixed with the second surfactant dose. Each animal received approximately $3 \times 10^{4} \mathrm{~Bq}$ of radioactivity. Each surfactant instillation was preceded by adding the microspheres to the surfactant and by gently stirring to mix the microspheres with the surfactant. Fifteen minutes after the PEEP was decreased to $490.3 \mathrm{~Pa}(5$ $\mathrm{cm} \mathrm{H}_{2} \mathrm{O}$ ), the artificial ventilation was interrupted, and the surfactant was immediately instilled through a side lumen of the tube in approximately $45 \mathrm{~s}$. After the instillation, the side lumen of the tube was flushed with $1.5 \mathrm{~mL}$ of $0.9 \% \mathrm{NaCl}$ to remove the residue of the surfactant, and then the artificial ventilation was resumed. During the procedure the supine position of the rabbits was unaltered. The same surfactant instillation procedure was repeated after $2 \mathrm{~h}$. The rabbits were ventilated for a period of $15 \mathrm{~min}$ after the second dose of surfactant to ensure spreading of the surfactant in the same way as was done in our previous surfactant distribution study (16).

Processing of the lungs. Fifteen minutes after the second surfactant dose, the rabbits were killed with an overdose of pentobarbital. The lungs were processed according to the protocol that we described previousiy (16). In short, the lungs were removed from the chest, separated into lobes, and frozen in liquid nitrogen. The frozen upper, middle, and lower lobes of the right lung were each cut into 33 pieces, the left upper lobe into 41 pieces, and the left lower lobe into 60 pieces. Each piece of lung tissue was weighed on an analytical balance with a resolution of $0.1 \mathrm{mg}$ (Mettler H35, Mettler-Toledo AG, Zürich, Switzerland). The radioactivity of the ${ }^{141} \mathrm{Ce}$ - and ${ }^{103} \mathrm{Rn}$-labeled microspheres was measured.
The distribution of the first surfactant dose was studied by the ${ }^{141} \mathrm{Ce}$ radioactivity, the second surfactant dose by ${ }^{103} \mathrm{Rn}$ radioactivity, and the total distribution by adding both the ${ }^{141} \mathrm{Ce}$ and the ${ }^{103} \mathrm{Rn}$ radioactivity. To assess the distribution of the endotracheally instilled surfactant over the 200 different lung pieces, the radioactivity was expressed as counts $/ \mathrm{min} / \mathrm{mg}$ of lung tissue in each piece. Then the mean counts $/ \mathrm{min} / \mathrm{mg}$ of all the lung pieces was determined for every rabbit, and in each piece of lung tissue the ratio of the actual counts/min/mg and the mean counts/min/mg were calculated. In this way, a normalized value for the radioactivity per $\mathrm{mg}$ was obtained for every piece of lung tissue. We grouped the normalized values in distribution intervals of $10 \%$. Histograms were obtained plotting the number of lung pieces in the $10 \%$ distribution intervals. Pieces with a normalized value of $<0.1$ or $>2.0$ were grouped at the extremes of the distribution intervals. In this way histiograms were obtained for the distribution of the first, second, and total dose, respectively. To compare the distribution in the different lobes, we calculated the percentage of pieces with a normalized value between arbitrarily chosen limits of 0.8 and 1.2. A higher percentage of lung pieces in this distribution interval represents a more homogeneous distribution of the administered surfactant.

To assess the relationship between the distribution of the first and second surfactant dose in each lobe, the radioactivity of $\mathrm{Ce}$ was plotted against the radioactivity of $\mathrm{Rn}$.

To obtain a quantitative impression of the amount surfactant that the different lung pieces received, we counted the number of lung pieces that received less surfactant than the calculated endogenous surfactant pool. The endogenous surfactant pool for adult rabbits is approximately $10 \mathrm{mg} \cdot \mathrm{kg}$ body weight (18). Using the following formula, the amount of endogenous surfactant per lung piece can be calculated:

Amount of endogenous surfactant $=$

$$
\frac{\text { weight of lung piece }}{\text { total lung weight }} \times \text { body weight } \times 10 \text {. }
$$

The amount of exogenous surfactant received per lung piece after the first and second dose can be calculated by using the following formulas:

Amount of exogenous surfactant (first dose $)=$

${ }^{141} \mathrm{Ce}$ radioactivity lung piece

${ }^{141} \mathrm{Ce}$ radioactivity total surfactant dose $\times$ body weight $\times 100$, Amount of exogenous surfactant (first + second dose $)=$ $\left({ }^{141} \mathrm{Ce}+{ }^{103} \mathrm{Rn}\right)$ radioactivity lung piece $\left({ }^{141} \mathrm{Ce}+{ }^{103} \mathrm{Rn}\right)$ radioactivity total surfactant dose $\times$ body weight $\times 150$.

Measurement of blood gases. Blood samples for the determination of arterial $\mathrm{PO}_{2}, \mathrm{PCO}_{2}$, and $\mathrm{pH}$ were obtained from the left carotid artery. Samples were taken before and after the lung lavage procedure. The effect of surfactant on the blood 
gases was determined by taking samples $15 \mathrm{~min}$ before and 15 min after surfactant instillation. Samples were analyzed using an ABL 330 blood gas analyzer (Radiometer Co., Copenhagen, Denmark).

Statistical analysis. All data are presented as means \pm SD. Statistical analysis was assessed by the Wilcoxon signed rank test for comparison of the arterial blood gas data and the calculated endogenous surfactant pool after the first and second dose, respectively. Differences between the groups were tested by analysis of variance. Linear regression analyses were used to analyze the Ce to $\mathrm{Rn}$ radioactivity data. Statistical significance was assumed when the $p$ value was less than 0.05 .

\section{RESULTS}

Arterial blood gas data. In all rabbits there was a significant increase in $\mathrm{PO}_{2}$ after the first and second dose of surfactant. Arterial $\mathrm{PO}_{2}$ increased from $5.7 \pm 1.1$ to $10.6 \pm 2.0 \mathrm{kPa}(p<$ $0.05) 15 \mathrm{~min}$ after the first and from $20.1 \pm 3.8$ to $30.1 \pm 2.5$ $\mathrm{kPa}(p<0.05) 15$ min after the second dose. The arterial $\mathrm{PCO}_{2}$ and $\mathrm{pH}$ did not change after surfactant treatments (Table 1).

Distribution of surfactant. The distribution histograms of the first, second, and total dose of surfactant showed a similar pattern of nonuniform distribution (Fig. 1). A large number of pieces in the distribution interval $<0.1$ indicates that a substantial part of the lung receives probably very little surfactant after instillation. The number of pieces in the distribution interval $<0.1$ is decreased for the total dose when compared with the first dose. Concurrently, we found also a large number of pieces in the distribution interval $>2.0$, indicating that a significant part of the lung received a large quantity of surfactant. The nonuniform distribution of the surfactant after the first and sccond dose is shown by the low percentage of lung pieces with a normalized value between 0.8 and 1.2. The percentage of lung pieces with a normalized value between 0.8 and 1.2 in the different lung lobes was comparable after the first and second dose of surfactant (Table 2), indicating that the distribution was not improved.

The Ce to $\mathrm{Rn}$ radioactivity in the five lung lobes of all six animals was logarithmically plotted (Fig. 2). The correlation per rabbit for the different lung lobes is given in Table 3 . The correlations widely ranged per lung lobe for all rabbits and per rabbit for the different lobes.

The percentage of the number of lung pieces that received an amount of surfactant that was less than the calculated endogcnous surfactant pool decreased significantly from $12.5 \pm$ $3.2 \%$ to $8.5 \pm 3.0 \%(p<0.05)$ after the first and second dose, respectively (Table 4 ).

Table 1. Arterial $\mathrm{PO}_{2}, \mathrm{PCO}_{2}$, and $\mathrm{pH}$ before and after surfactant instillation in rabbits with severe respiratory failure

\begin{tabular}{lcccc} 
& $\begin{array}{c}\text { Before } \\
\text { 1st dose }\end{array}$ & $\begin{array}{c}\text { After } \\
\text { 1st dose }\end{array}$ & $\begin{array}{c}\text { Before } \\
\text { 2nd dose }\end{array}$ & $\begin{array}{c}\text { Aftcr } \\
\text { 2nd dose }\end{array}$ \\
\hline $\mathrm{PO}_{2}$ & $5.70 \pm 1.1$ & $10.60 \pm 2.0^{*}$ & $20.10 \pm 3.8$ & $3\left(0.10 \pm 2.5^{*}\right.$ \\
$\mathrm{PCO}_{2}$ & $5.30 \pm 1.5$ & $4.70 \pm 1.3$ & $4.20 \pm 1.2$ & $3.90 \pm 1.2$ \\
$\mathrm{pH}$ & $7.32 \pm 0.07$ & $7.38 \pm 0.09$ & $7.43 \pm 0.11$ & $7.43 \pm 0.11$ \\
\hline
\end{tabular}

$* p<0.05$ by means of the Wilcoxon signed rank test.

\section{DISCUSSION}

In this study we have demonstrated that a second dose of surfactant is distributed over the lung in a similar nonuniform way as the first dose. This second dose of surfactant does not lead to a more uniform distribution. These findings suggest that the surfactant of the second dose is directed to parts of the lung that have been supplemented by the first dose. However, if that were true, then we would have found a high positive correlation between the $\mathrm{Ce}$ and $\mathrm{Rn}$ radioactivity, the markers of the first and sccond dose of surfactant, respectively. In case of a high negative correlation between the two isotopes, we would have interpreted the data as most of the surfactant of the second dose being directed to areas that did not receive surfactant with the first dose. In the present study, we found that the correlations widely ranged, both for the same lung lobes for the different rabbits as well as per rabbit for the different lung lobes (Table 3). We therefore conclude that the second dose of surfactant is directed both to surfactant-supplemented and surfactant-deficient areas. This conclusion is further supported by the fact that the percentage of lung pieces that initially received an amount of surfactant that was less than the endogenous surfactant pool decreased after the second dose was given. Furthermore, the rise in arterial $\mathrm{PO}_{2}$ after the second dose of surfactant reflects an increase in the functional residual capacity of the lung.

In a recent study by Ueda et al. (19), the effect of a sccond dose of surfactant on the distribution was also studied by applying different instillation techniques. In contrast to our observations, they found a higher correlation coefficient (0.600.74 ) between the first and sccond surfactant dose. Furthermore, they found little improvement in oxygenation after the second dose, which was given $2 \mathrm{~h}$ after the initial dose. They hypothesized that the surfactant preferentially went to those lung areas that were open and receiving ventilation as a result of the initial treatment. The difference observed between the two studies may be explained by differences in surfactant preparations, instillation technique, and the animal model (preterm lambs and lung-lavaged adult rabbits, respectively).

It could be argued that the increase in $\mathrm{PO}_{2}$ is not attributable to an improved distribution of the second dose to those areas that did not receive surfactant the first time but just by increasing the total amount of exogenous surfactant. For example, the rise in $\mathrm{PO}_{2}$ after the second dose may be explained by the total higher dose and not necessarily be related to distribution. Although we did not study the effect of a single surfactant dose of $150 \mathrm{mg} / \mathrm{kg}$ on the arterial $\mathrm{PO}_{2}$, we think it is unlikely that a 2-fold increase in arterial $\mathrm{PO}_{2}$, with an interval of $2 \mathrm{~h}$, would occur after a single surfactant dose, just as in the present study. In fact, to our knowledge, a 2-fold increase after a single surfactant dose has not been described before. Therefore, wc think the second increase in $\mathrm{PO}_{2}$ is an effect of distribution rather than of a total higher dose. In addition, we have also not studied the effect of a single surfactant dose of $150 \mathrm{mg} / \mathrm{kg}$ on the percentage of lung picces that reccived an amount of surfactant that was less than the endogenous surfactant pool. It can be anticipated that the percentages of lung pieces will decrease by increasing a single surfactant dose because more 
Left upper lobe

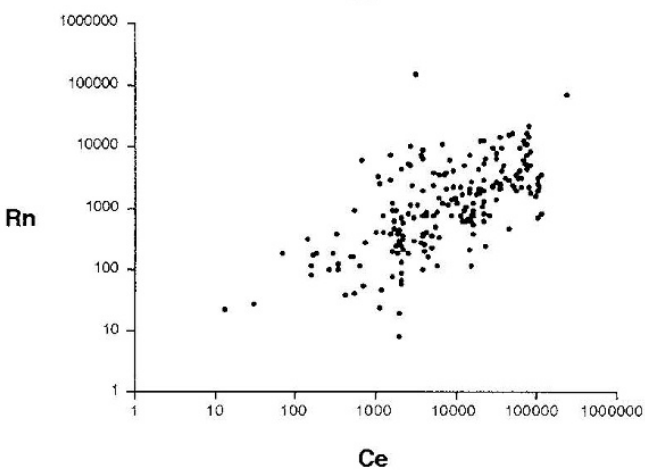

Right upper lobe

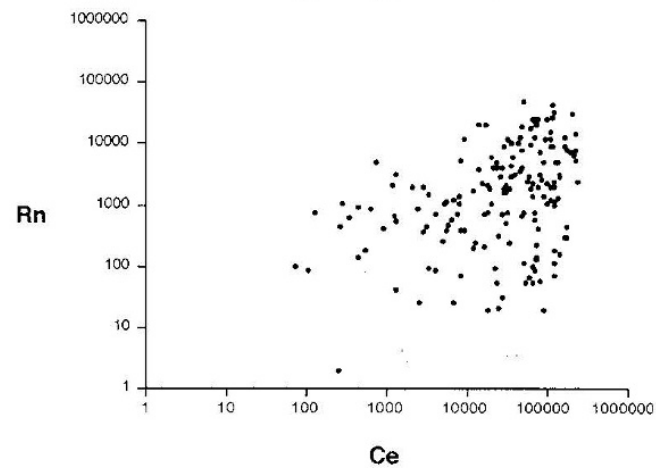

Left lower lobe

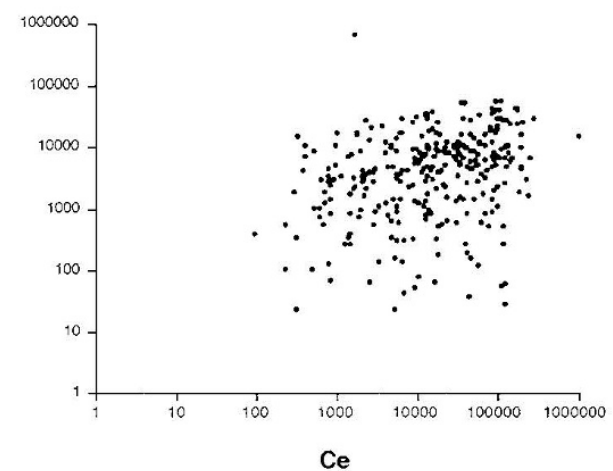

Right middle lobe

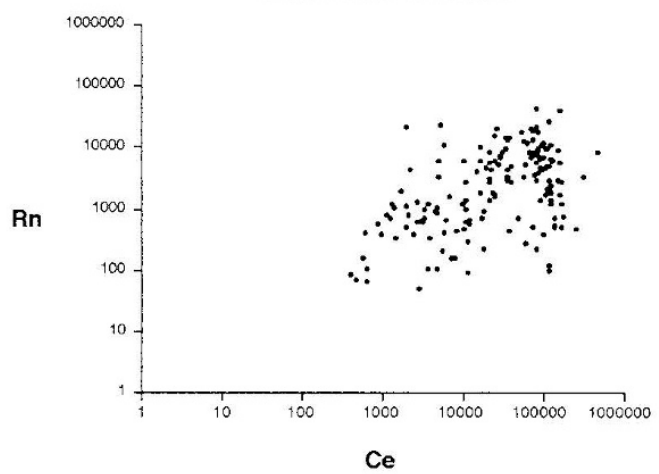

Right lower lobe

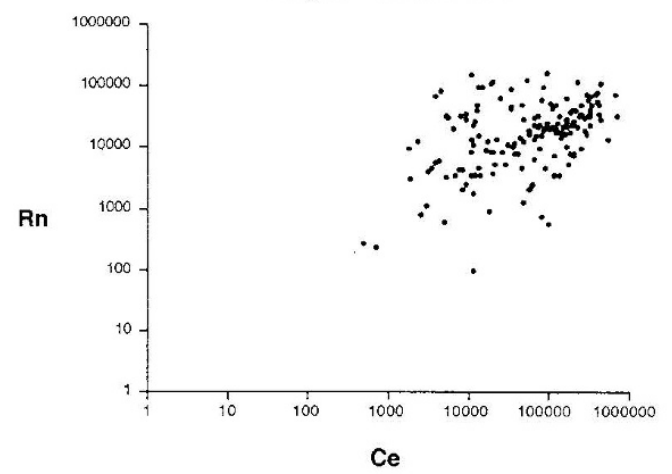

Figure 1. Normalized distribution of exogenous surfactant for rabbits with severe respiratory failure treated with two doses of surfactant. All values were calculated as described in "Methods" and are expressed as mean number of pieces in each $10 \%$ distribution interval. A normalized value of 1.0 represents a uniform distribution. The distribution histograms of the first $(A)$, second $(B)$, and total dose $(C)$ of surfactant showed a similar pattern of nonuniform distribution. A large number of lung pieces received either a small amount of surfactant (normalized value $<0.1$ ) or a large amount of surfactant $($ normalized value $>2.0$ ). The number of pieces in the distribution interval $<0.1$ is decreased for the total dose when compared with the first dose.

Table 2. Distribution of surfactant expressed as the percentage of lung pieces with a normalized value between 0.8 and 1.2 in the different lobes of the lungs and in the total lung

\begin{tabular}{lccccrc}
\hline Dose & $\begin{array}{c}\text { Left upper } \\
\text { lobe }(\%)\end{array}$ & $\begin{array}{c}\text { Left lower } \\
\text { lobe }(\%)\end{array}$ & $\begin{array}{c}\text { Right upper } \\
\text { lobe }(\%)\end{array}$ & $\begin{array}{c}\text { Right middle } \\
\text { lobe }(\%)\end{array}$ & $\begin{array}{c}\text { Right lower } \\
\text { lobe }(\%)\end{array}$ & $\begin{array}{c}\text { Total lung } \\
(\%)\end{array}$ \\
\hline First & $21.0 \pm 8.4$ & $20.0 \pm 7.5$ & $20.6 \pm 16.2$ & $24.7 \pm 12.4$ & $23.6 \pm 17.5$ & $16.5 \pm 8.4$ \\
Second & $15.9 \pm 6.4$ & $21.0 \pm 5.8$ & $15.9 \pm 1.6$ & $21.2 \pm 9.4$ & $29.7 \pm 10.8$ & $14.3 \pm 2.1$ \\
Total & $23.6 \pm 11.5$ & $1.8 .0 \pm 7.8$ & $22.4 \pm 17.6$ & $25.9 \pm 14.6$ & $25.5 \pm 18.1$ \\
\hline
\end{tabular}

No significant difference was observed. 
A

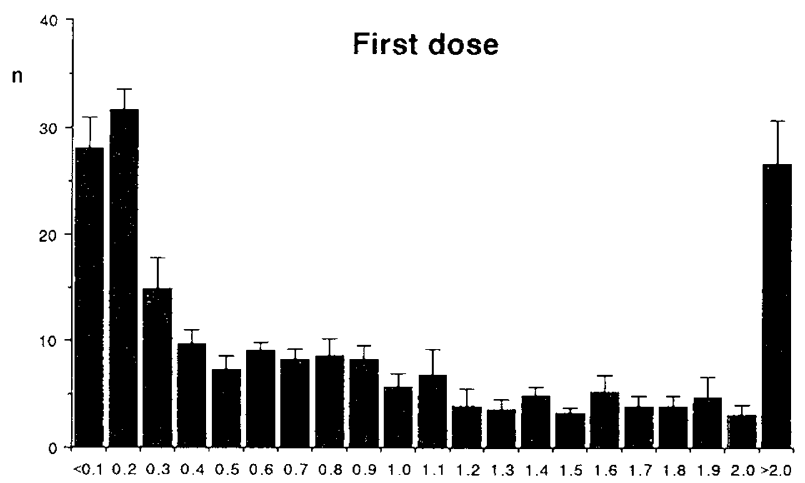

B

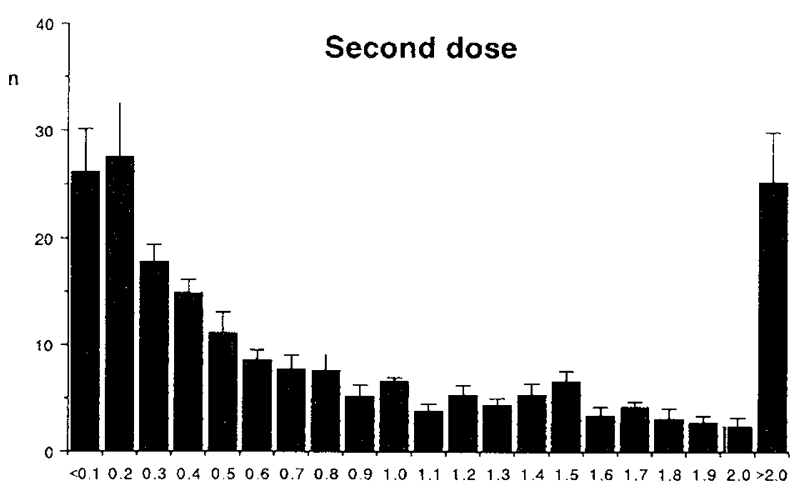

C

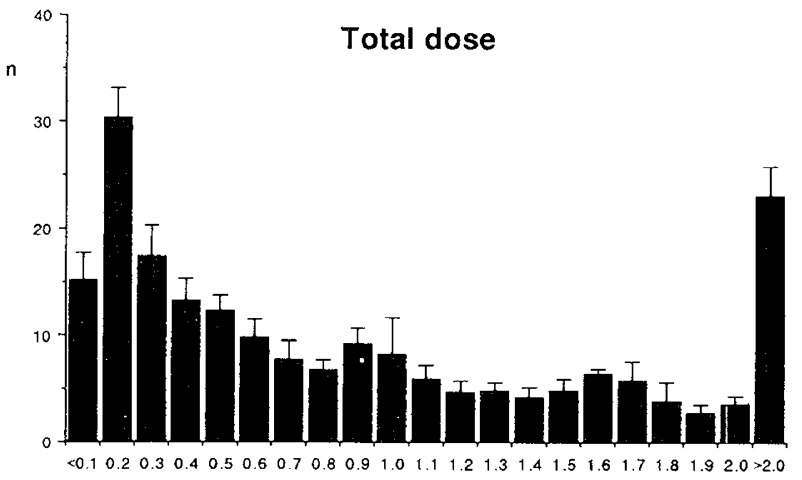

Figure 2. Correlations between $\mathrm{Ce}$ and $\mathrm{Rn}$ radioactivity representing the first and the second surfactant dose, respectively, in the lungs of rabbits with severe respiratory failure. Both parameters are expressed logarithmically and given for the five lung lobes of the six animals.

areas will have a surfactant level that is higher than the cutoff values of the endogenous surfactant pool. In this study, using our technique, it is impossible to discriminate whether the decrease in the percentage of lung pieces is an effect of distribution or of a higher dose. However, based on the other results, the correlation between the $\mathrm{Ce}$ and $\mathrm{Rn}$ microspheres, the second rise in arterial $\mathrm{PO}_{2}$, we think that the decrease is most likely a distribution effect.

It is currently assumed that the optimal clinical effect of surfactant therapy will occur when the endotracheally instilled surfactant is distributed in an uniform way throughout the lung. However, as yet, little is known of the distribution of surfactant after administration, particularly in the clinical situation. Investigators have tried to study the initial distribution of exogcnous surfactants in newborns with RDS, but both studies were unable to assess the distribution at the alveolar level $(20,21)$.
Table 3. Correlations between $\mathrm{Ce}$ and Rn radioactivity, representing the first and the second surfactant dose, respectively, per rabbit for the five lung lobes

\begin{tabular}{cccccc} 
Rabbit & $\begin{array}{c}\text { Left } \\
\text { upper }\end{array}$ & $\begin{array}{c}\text { Left } \\
\text { lower }\end{array}$ & $\begin{array}{c}\text { Right } \\
\text { upper }\end{array}$ & $\begin{array}{c}\text { Right } \\
\text { middle }\end{array}$ & $\begin{array}{c}\text { Right } \\
\text { lower }\end{array}$ \\
\hline 1 & -0.077 & -0.086 & -0.021 & -0.004 & 0.621 \\
2 & 0.417 & -0.085 & 0.183 & -0.237 & -0.069 \\
3 & 0.728 & 0.120 & 0.462 & 0.103 & 0.271 \\
4 & 0.823 & 0.160 & 0.290 & 0.258 & 0.211 \\
5 & 0.403 & 0.397 & 0.841 & 0.760 & 0.371 \\
6 & 0.220 & 0.243 & 0.354 & 0.321 & 0.124 \\
\hline
\end{tabular}

Table 4. The percentage of the number of lung pieces per rabbit that received an amount of surfactant that was less than the calculated endogenous surfactant pool after the first and second dose, respectively

\begin{tabular}{ccc}
\hline Rabbit & After 1st dose & After 2nd dose \\
\hline 1 & 15.0 & 9.8 \\
2 & 9.8 & 5.5 \\
3 & 8.4 & 5.8 \\
4 & 14.5 & 11.5 \\
5 & 11.1 & 6.5 \\
6 & 16.4 & 12.1 \\
Average & $12.5 \pm 3.2$ & $8.5 \pm 3.9^{*}$ \\
\hline
\end{tabular}

$* p<0.05$ by means of the Wilcoxon signed rank test.

In experimental studies, it has been demonstrated that the homogeneity of surfactant distribution is related to the instillation technique and to the fluid volume in which the surfactant is mixed $(16,22,23)$. Segerer et al. (22) demonstrated that bolus instillation of surfactant resulted in a reasonably homogeneous pulmonary surfactant distribution in contrast to slow tracheal infusion of surfactant. Besides the instillation technique, the fluid volume in which the surfactant is mixed is another important factor that influences pulmonary surfactant distribution. Gilliard et al. $(23)$ and we $(16,24)$ found improvement in the surfactant distribution by suspending the surfactant concentration in a larger fluid volume. This parallels the observation of Jobe et al. (25) who demonstrated that the distribution of surfactant is fairly homogeneous if instilled before the first breath, when the lungs are still filled with fetal lung liquid. We have demonstrated that endotracheal instillation of a large volume of diluted surfactant results in a uniform distribution to the lung (16). However, after this treatment, it is impossible to ventilate the lungs adequately using the normal pressure range (26). Recently we have shown that this problem can be overcome by the use of an extracorporeal life support system (26). However, this indicates that instillation of a large fluid volume of diluted surfactant, so that a uniform distribution can be obtained, is not yet clinically feasible.

We therefore investigated whether the instillation of a second dose of surfactant would promote a uniform distribution throughout the lung. In clinical practice, multiple doses of surfactant are administered because of a relapse in lung function. It has been shown in some studies that the outcome in terms of morbidity and mortality in patients with severe RDS was favorable after a multiple-dose treatment (12-15). Better oxygenation during the first days of life after surfactant treatment was reported by Dunn et al. (15) after a multiple-dose 
strategy. Liechty et al. (12) demonstrated that multiple doses of surfactant given after diagnosis of RDS in premature infants weighing 600-1750 g reduced mortality and morbidity. We had hypothesized that a more uniform distribution of surfactant would be achieved after multiple dose treatment, and this would contribute to a more favorable outcome in RDS patients. However, in our study the instillation of a second dose did not resuli in a uniform distribution of surfactant.

In conclusion, we have demonstrated that a second dose of surfactant does not promote a uniform distribution to the lung but does result in a significant rise in arterial $\mathrm{PO}_{2}$. The second dose is most likely directed to lung parts that initially received surfactant as well as to areas that did not receive surfactant with the first dose. We assume that the surfactant-deficient areas were aerated after this second dose, resulting in improved oxygenation.

Acknowledgments. Alveofact surfactant vials for this study were kindly provided by Dr. K. Thomae GmbH. The authors thank A. van Zanten for her assistance and hospitality at the Department of Nuclear Medicine.

\section{REFERENCES}

1. Fujiwara '1, Chida S, Watabe Y, Maeta II, Morita T, Abe T 1980 Artificial surfactant therapy in hyaline-membranc discase. Lancet $1: 55-59$

2. Collaborative European Multicenter Study Group 1988 Surfactant replacement therapy for severe neonatal respiratory distress syndrome: an international randomized clinical trial. Pediatrics 82:683-691

3. Kwong MS, Egan EA, Nottcr RH, Shapiro DL 1985 Double-blind trial of calf lung surfactant extract for the prevention of hyaline membrane disease in extremely premature infunts. Pediatrics 76:585-592

4. Halliday HL, McGlure G, McReid M, Lappin TRJ, Meban C, Thomas PS 1984 Controlled trial of artificial surfactant to prevent respiratory distress syndrome. Lancet $1: 476-478$

5. Wilkinson A, Jenkins PA, Jeffrey JA 1985 Two controlled clinical trials of dry artificial surfactant: early effects and later outcome in babics with surfactant deficiency. Lancet 2:287-291

6. Gitlin JD, Soll RF, Parad RB, Horbar JD, Feldman HA, Lucey JF, Tacusch HW 1987 Randomized controlled trial of exogeneous surfactant for the treatment of HMD Pediatrics 79:31-37

7. Raju TNK, Vidyasagar D, Bhat R, Sobel D, McCulloch KM, Anderson M, Maeta H Levy PS, Furner S 1987 Double blind controlled trial of single-dose treatment with bovine surfactant in severe respiratory distress syndrome. Lancet 1:65I-656

8. Hallman M, Merritt TA, Jarvenpaa AL, Boynton B, Mannino F, Gluck L, Moore T, Edwards D 1985 Exogeneous human surfactant for treatment of severe respiratory distress syndrome: a randomized prospective clinical trial. Pediatrics 106:963-969
9. Merritt TA, Hallman M, Bloom BT, Berry CB, Benirschke K, Sahn D, Key T, Edwards D, Jarvenpaa A-L, Pohjavuori M, Kankanpala K, Kunnas M, Paatero H, Rapola J, Jaaskelainen $\int 1986$ Prophylactic treatment of very premature inlants with human surfactant. N Engl J Med 315:785-790

10. Kendig JW, Notter RH, Cox C, Aschner JL, Benn S, Bernstein RM 1988 Surfactant replacement therapy at birth: final analysis of a clinical trial and comparisons with similar trials. Pediatrics 82:756-762

11. Auten RL, Notter RH, Kendig JW, Davis JM, Shapiro DI, 1991 Surfactant treatment of full-term newborns with respiratory failure. Pediatries 87:10)1-107

12. Liechty EA, Donovan E, Purohit MD, Gilhooly J, Feldman B, Noguchi A, Denson SE, Schgal SS. Gross I, Stevens D, Ikegami M, Zachman RI, Carrier ST, Gunkel JH, Gold AJ 199! Reduction of neonatal morlatity after multiple doses of bovine surfactant in low birth weight neonates with respiratory distress syndrome. Pediatrics $88: 19-28$

13. Hockstra RE, Jackson JC, Myces TF, Fiantz III ID, Stern ME, Powers WF, Maurer M, Rayc JR, Carrier ST, Gunkel J1l, Gold AJ 1991 Improved neonatal survival following multiple doses of bovine surfactant in very premature infants at risk for respiratory distress syndrome. Pediatrics $88: 10-18$

14. I,ong WA, Thompson T, Sundell H, Schumacher R, Volberg F, Guthric R 1991 Effects of two rescue doses of a synthetic surfactant on mortality in 700:1300 gram inlants with RDS. J Pediatr 118:595-605

15. Dunn MS, Shennan AT, Possmayer F 1990 Single- versus multiple-dose surfactant replacement therapy in neonates of 30 to $36 \mathrm{wk}$ gestation with respiratory distress syndrome. Pediatrics 86:564-571

16. Van der Bleek J, Plötz FB, Van Overbeek F, Heikamp A, Wildevuur ChRH, Okken A, Bambang Octomo S 1993 Distribution of exogenous surfactant in rabbits with severe respiratory failure: the effect of volume. Pediatr Res 34:154-158

17. Bambang Oetomo S, Reijngoud DJ, Ennema JJ, Okken A, Wildevuur ChRH 1988 Surfactant replacement therapy in surfactant deficient rabbits: early effects, lung function, and biochemical aspects. Lung 166:65-73

18. Jobe A 1989 Metabolism of endogenous surfactant and exogenous surfactants used for replacement therapy. In: Shapiro DL, Notter RH (eds) Surfactant Replacement Therapy. Alan R Liss, Inc, New York, pp 99-125

19. Ucda T, Ikcgami M, Rider ED, Jobe AH 1994 Distribution of surfactant and ventilation in surfactant-treated preterm lambs. J Appl Physiol 76:45-55

20. Ferrara TB, Hockstra RE, Johnson P, Vernier RI. 1987 Localization of surfactant in neonatal lung after exogeneous administration. J Pediatr 111:46.3-466

21. Charon A, Taleusch HW, Fitzgibbon C. Snith GB, Treves ST, Phelps DS 1989 Factors associated with surfactant treatment response in infants with severe respiratory distress syndrome. Pediatrics 83:348-354

22. Segerer H, Van Gelder W, Angenent FWM, Van Woerkens LJPM, Curstedt $T$, Obladen M, Lachman B 1993 Pulmonary distribution and efficacy of exogenous surfactant in lung-lavaged rabbits is influeneed by the instillation technique. Pediatr $\operatorname{Res} 34: 490-494$

23. Gilliard N, Richman PM, Merrit TA, Spragg RG 1990 Effect of volume and dose on the pulmonary distribution of exogeneous surfactant administered to normal rabbits or to rabbits with oleic acid lung injury. Am Rev Respir Dis 141:743-747

24. Bambang Oetomo S, Lcwis J, Ikcgami M, Jobe AH 1990) Surfactant treatments alter cndogeneous surfactant metabolism in rabbit lungs. J Appl Physiol 68:1590-1596

25. Jobe A, Ikegami M, Jacobs H, Jones S 1984 Surfactant and pulmonary blood flow distribution following treatment of premalure lambs with natural surfaclant. J Clin Invest 73:848-850

26. Plötz FB, Mook PH, Hcikamp A, Brus F, Okken A, Bambang Oetomo S, Wildevuur ChRH 1993 Large volume instillation of surfactant during extracorporeal life support improves lung function in lung lavaged rabbits ASAIO J 39:470-474 